\title{
Determinants of intention to use social media for health purposes among Jewish women in Israel: A cross-sectional study
}

\author{
Dennis Rosenberg, Rita Mano, Gustavo S. Mesch \\ University of Haifa, Israel
}

Received: May 26, 2019

DOI: $10.5430 /$ jha.v8n $5 \mathrm{p} 10$

\author{
Accepted: August 4, 2019 \\ Online Published: August 9, 2019 \\ URL: https://doi.org/10.5430/jha.v8n5p10
}

\begin{abstract}
Women use the Internet more for health purposes than men, probably due to their gender socialization as caregivers. Indeed, women's use of social media for health is not a one-time occurrence but is expected to continue for a long time to come. Hence, it is important to understand women's future intention to use social media for health purposes. This study integrated health empowerment, health beliefs and digital inequality perspectives to explain this intention among Jewish female social media users $(\mathrm{N}=94)$. The data were collected through a telephone survey. The results indicated that searching for health information on social media and cues to action are consistent predictors of women's intention to use social media for health purposes. With the exception of marital status, no effect of socio-demographic variables was found. Health empowerment approach and health belief model are, therefore, the best predictors of future intention to use social media for health. Women should be encouraged by their communities to expand their experience with social media, since it may serve as a source of health empowerment. In addition, they must be encouraged to be more attentive to internal or external stimuli in maintaining or changing their health behavior.
\end{abstract}

Key Words: Social media, Search for health information, Women's health, Intention to use

\section{INTRODUCTION}

Traditionally, patients turned to healthcare providers when they had questions regarding their health. ${ }^{[1]}$ For the past two decades, the Internet has been used for health purposes, ${ }^{[2,3]}$ including searching for online health information $(\mathrm{OHI}){ }^{[2-4]}$ Search for OHI refers to purposefully searching for information on the Internet on various health-related topics, such as treatments, diagnoses, health institutions and medications, as well as nutrition and physical activity. ${ }^{[5]}$ Information on these topics can also be found on social media.
Social media refers to a group of the online applications that allow their users to communicate, generate and exchange content. ${ }^{[6]}$ Among them are content-sharing services such as YouTube or Instagram, ${ }^{[7]}$ social networking sites (hereinafter: SNS) such as Facebook, ${ }^{[8,9]}$ forums, ${ }^{[10]}$ microblogs such as Twitter, ${ }^{[11]}$ and so on. The content may include pictures, links to other webpages, videos and more. ${ }^{[12]}$ The multiple advantages of social media, including large scope of content ${ }^{[13]}$ and the possibility of receiving immediate feedback to published content, ${ }^{[1]}$ have facilitated its entry into the health domain. ${ }^{[13]}$ Social media is now widely used for

*Correspondence: Rita Mano; Email: ritamano@research.haifa.ac.il; Address: University of Haifa, Israel. 
searching for health information. ${ }^{[14]}$

Gender has always been a focus of attention in studies on health and the Internet. Such studies referred both to gender differences in health-related use of the Internet ${ }^{[15]}$ or social media $^{[16]}$ and to health-related Internet use by women in particular. ${ }^{[17,18]}$ However, these studies focused primarily on health-related Internet behavior at a specific time point without addressing its sustained use.

Yet health-related social media use, including searching for health information, is not necessarily something that occurs only once. Such behavior can be sustained and may entail continuous benefits for one's own health. ${ }^{[19]}$ In the case of women, health-related social media use offers twofold benefits. First, women generally tend to search for OHI more frequently than men, ${ }^{[20,21]}$ so they also gain ongoing benefits. Second, sustained social media use may benefit not only them but also their family members, ${ }^{[22]}$ since women's health-related use of the Internet is generally attributed to their role as family caregiver ${ }^{[21,22]}$ and health manager. ${ }^{[23]}$ Therefore, studying the intention to use social media for health among women is of major importance. The goal of the current study is to examine the factors affecting this intention among women.

Behavioral intention to adopt or use technology is a welldocumented issue in various scientific fields, including information systems ${ }^{[24]}$ e-government ${ }^{[25,26]}$ and health and Internet research. ${ }^{[2]}$ Studies investigating intention to adopt technology usually employ a single theoretical model (in most cases from the field of information systems research), thereby reflecting only one perspective and sometimes not even controlling for users' socio-demographic background characteristics.

The current study will contribute to the field in three ways. First, it will extend knowledge regarding women's use of health-related social media. Previous studies ${ }^{[15,22,27]}$ examined health-related use of the Internet in general. Moreover, sustained use of health-related social media has received little research attention, particularly among women. Second, this study employs two distinct theoretical concepts, namely, technology and health attitudes, and considers the sociodemographic background of its female users. These concepts provide different perspectives and consider different factors (as described in detail in the literature review). Third, at the empirical level, the study provides generalized findings regarding the studied phenomenon by employing multivariate statistical analysis. This is especially important in the field of health and social media studies, which is characterized by a relatively small number of quantitative studies ${ }^{[16,28]}$ and a dominance of qualitative research. ${ }^{[1,9,19,29]}$

\section{LiteratURE REVIEW}

Although knowledge about the determinants of health-related Internet use is extensive, little is known about the determinants of the intention to use social media for health purposes. This research suggests that this intention can be affected by searching for OHI (reflecting health empowerment processes), as well as by health beliefs and socio-demographic background (reflecting digital inequality).

\subsection{Health empowerment}

The term "health empowerment" refers to taking personal responsibility for one's own health. ${ }^{[30]}$ In modern societies, assuming responsibility for one's own health has become a key component of public health management. ${ }^{[31]}$ Health empowerment is even more relevant for women than for men, since women are expected to be the source of health empowerment not only for their life partners but also for their communities. ${ }^{[22]}$ Indeed, studies show that women both search for $\mathrm{OHI}^{[4,22]}$ and use social media for health purposes ${ }^{[16]}$ more than men. Therefore, $\mathrm{OHI}$ found by women may contribute to the health of their families and of their communities, which rely on women in adopting healthy behaviors. ${ }^{[22]}$ In addition, in modern societies women experience tension between work and family. The Internet and social media increase their likelihood of successfully handling both these spheres. ${ }^{[22]}$ In summary, women who search for OHI bring benefits to themselves and to their social networks. Therefore, women who already engage in this behavior are more likely to continue reaping these benefits in the future than those who do not search for OHI. Thus, it is hypothesized that:

H1: Women who search for OHI on social media are more likely to intend to use social media for this purpose in the future than women who do not search for OHI on social media.

\subsection{Health beliefs}

Research indicates that women have a greater tendency than men to experience chronic diseases, distress and limited functionality. ${ }^{[32]}$ This tendency may affect their personal health beliefs. Therefore, among other reasons, women are likely to use social media for health purposes in order to obtain more positive health beliefs. ${ }^{[33]}$ Health beliefs may also affect women's health-related social media use. One of the most known and researched models explaining healthrelated behaviors as a function of health-related beliefs is the health belief model (henceforth: HBM) ${ }^{[34]}$ This model was developed in order to explain the variance in use of public health services. ${ }^{[35]}$ According to it, the likelihood that individuals will take health-related preventive action depends on their perception of vulnerability to their health condition, 
severity of its consequences, benefits of taking preventive action, costs of taking such action, presence of environmental triggers (cues to action) that may lead to taking preventive action, and a confidence (self-efficacy) in ability to take such action. ${ }^{[34]}$ Since its original conception, it has also been employed in health and Internet studies to explain search for $\mathrm{OHI}$ and health communication. ${ }^{[5]}$

Beliefs regarding the cues to action require special attention $^{[34]}$ since this construct has received insufficient attention in studies testing the HBM. ${ }^{[36,37]}$ Cues to action refer to environmental triggers or stimuli that motivate an individual to change a current health behavior. ${ }^{[34,38]}$ Higher evaluation of cues to action may act as a strong trigger for individuals to adopt preventive behavior as a reflection of their previous experience with risk, ${ }^{[38]}$ as opposed to those whose evaluation of such cues is lower. This is particularly relevant for women, who are generally more sensitive, ${ }^{[39]}$ more attentive to environmental cues and more vulnerable to influence ${ }^{[40]}$ than are men. The intention to use social media for health purposes may serve women as preventive behavior resembling their current health-related Internet use. ${ }^{[5]}$ Therefore, it is hypothesized that:

$\mathrm{H} 2$ : Evaluation of cues to action by women is positively associated with their likelihood of intending to use social media for health purposes in the future.

\subsection{Digital inequality}

Finally, since women from various socio-demographic backgrounds use technology, it is important to consider these backgrounds, particularly in view of the consistent findings on inequalities between social groups in health-related Internet use. ${ }^{[16,27]}$

Social groups are divided along several lines in their healthrelated social media use. The first is marital status. In the case of women, having a steady life partner means receiving health-related social control from their partner. Non-married women, in contrast, tend to receive such control from other sources. ${ }^{[41]}$ Thus they are expected to rely more on social media for health issues than married women. The second socio-demographic factor is education. Enhanced cognitive skills that are attributed to those with more education enable individuals to better evaluate health information. ${ }^{[4]}$ In addition, individuals with higher education are more motivated to lead a healthy lifestyle ${ }^{[42]}$ and to participate in capitalenhancing online activities ${ }^{[43]}$ as compared to less educated individuals. The third factor is age. Older women who were socialized to technology use at a later stage of life may have more difficulties using the technology than younger women. ${ }^{[44]}$ The final factor is health status. Having a chronic health condition is known as a motivator for health-related Internet use. ${ }^{[4]}$ Thus, it is hypothesized that:

H3: Women's socioeconomic background affects their intention to use social media for health purposes.

\section{Methods}

This study is a part of a larger project investigating healthrelated social media use and its effect on health behavior in Israel. The project uses the mixed methods approach ${ }^{[45]}$ and includes a (preliminary) qualitative part and a (main) quantitative part. The purpose of the qualitative part was to assess the scope of health-related social media use and various aspects of its effect on health behavior changes. The quantitative part was aimed to establish the association between health-related social media use and the likelihood of changing health behaviors using statistical models. The quantitative analysis was carried out in three stages: a pilot survey and two waves of a large-scale telephone survey. The data for the current study were collected during the pilot survey, which took place in May-July 2016. The main purposes of the pilot survey were methodological (to prepare the questionnaire for the two waves of the survey) and empirical (to assess health-related social media use and health behaviors in general). Participants were asked for their consent to participate before they were surveyed. ${ }^{[46]}$

The entire project was approved by the Ethics Committee of the University of Haifa (Approval No. 246/17).

\subsection{Study population}

The population of the current study includes Jewish female social media users between the ages of 20-79 ( $\mathrm{N}=94)$ who were surveyed during the pilot study (the total number of respondents was 300). Since the questionnaire was administered in Hebrew, only those sufficiently proficient in Hebrew were interviewed. Due to the purposes mentioned above, there was no intention to collect a representative sample. Therefore, questionnaires in other languages commonly spoken in Israel (including Arabic and Russian) were not prepared for the current stage of the project.

As to the sample statistics, most of the participants are married $(85.3 \%)$, with an academic education (B.A. and higher) $(53.2 \%)$ and a mean age of about 47 years. Most of them have no chronic diseases $(70.7 \%)$ and do not search for $\mathrm{OHI}$ on social media $(73.4 \%)$. The detailed characteristics of the sample are outlined in Table 1.

\subsection{Study variables}

\subsubsection{Dependent variable}

Intention to use social media for health purposes - measured by a single item assessing agreement with a statement regard- 
ing future intention to use social media for health. Responses were on a Likert scale ranging from " 1 " (totally disagree) to "5" (totally agree).

\subsubsection{Independent variables}

(1) Searching for OHI on social media - a dichotomous variable. Women who reported not searching for $\mathrm{OHI}$ on social media represent an omitted category.

(2) Cues to action - a continuous variable computed by summing up the scores on two items (where a higher score represents higher influence of the cues). One item represented external cues (family and friends) while the other represented the internal cue (health status) (see items CTA1 and CTA2 in Table 2). Responses to the items included in this construct were on a Likert scale ranging from "1" (totally disagree) to " 5 " (totally agree).

The process of creating this variable included several stages. The first stage of the factor analysis included all 12 items. However, four items had to be eliminated because they negatively correlated with the respective factors, because they were loaded on two factors or because they were not loaded on any one of the factors extracted. The final run of the analysis, which provided an appropriate structure, included eight items and yielded three factors that explain $63.84 \%$ of the variance. The factor representing cues to action was elicited as the first factor. Three items were loaded on it (PBA2: 0.53, CTA1: 0.82 and CTA2: 0.89). This factor was the only one with an acceptable value of Cronbach's Alpha. ${ }^{[47]}$ Elimination of the item PBA2 yielded a higher reliability value, which surpasses the recommended limit of 0.7. ${ }^{[48]}$ The detailed results of the validity and reliability tests and the definitions of the items are shown in Table 2.

Table 1. Sample statistics ( $=94$, if not specified otherwise)

\begin{tabular}{ll}
\hline Variable Categories & Frequency (in \%) \\
\hline Intention to use for health purposes $(\mathbf{N}=\mathbf{9 2})$ & 44.6 \\
Not at all & 12.0 \\
To a small extent & 22.8 \\
To a medium extent & 6.5 \\
To a high extent & 14.1 \\
To a very high extent & \\
Education & 53.2 \\
Academic & 46.8 \\
Non-academic & \\
Marital status $(\mathbf{N}=\mathbf{7 5})$ & 85.3 \\
Married & 14.7 \\
Non-married & \\
Chronic health condition $(\mathbf{N}=\mathbf{9 2})$ & 29.3 \\
Yes & 70.7 \\
No & \\
Search for OHI on social media & 26.6 \\
Yes & 73.4 \\
No & $46.98(15.20)$ \\
\hline Age: mean $(S D)$ & $4.54(2.59)$ \\
\hline Cues to action $(\mathrm{N}=92):$ mean $(S D)$ & \\
\hline
\end{tabular}

Table 2. Results of the validity and reliability tests on items representing the HBM constructs

\begin{tabular}{|c|c|c|c|c|}
\hline Item & & $\begin{array}{l}\text { Cues to } \\
\text { action }\end{array}$ & $\begin{array}{l}\text { Threat and } \\
\text { benefits }\end{array}$ & $\begin{array}{l}\text { Health } \\
\text { self-efficacy }\end{array}$ \\
\hline CTA1 & My family and friends cue me that I have to change my health habits. & 0.82 & & \\
\hline CTA2 & My health conditions cue me that I have to change my health habits. & 0.89 & & \\
\hline PBA2 & I do not have enough money to change my health habits. & 0.53 & & \\
\hline PS1 & $\begin{array}{l}\text { If my health worsens, I will experience difficulties in functioning at } \\
\text { my workplace. }\end{array}$ & & 0.70 & \\
\hline PS2 & If my health worsens, it will damage my interpersonal relations. & & 0.70 & \\
\hline $\mathrm{PBE}$ & A change in health habits will improve my health. & & 0.76 & \\
\hline HSE1 & I have set a number of goals in order to improve my health. & & & 0.84 \\
\hline HSE2 & $\begin{array}{l}\text { I am able to reach the goals I have set to myself in order to improve } \\
\text { my health. }\end{array}$ & & & 0.75 \\
\hline HSE3 & I work on improving my health. & & & \\
\hline PV1 & Compared to people in my age group, my health is good. & & & \\
\hline PV2 & There is a history of chronic health diseases in my family. & & & \\
\hline PBA1 & I do not have enough time to change my health habits. & & & \\
\hline $\begin{array}{l}\text { Cronbach's } \\
\text { Alpha }\end{array}$ & & 0.637 & 0.592 & 0.454 \\
\hline $\begin{array}{l}\text { Cronbach's } \\
\text { Alpha revised }\end{array}$ & & 0.755 & --- & --- \\
\hline
\end{tabular}


(3) Marital status - a dichotomous variable, with married (or cohabiting) women as a reference category.

(4) Education - a dichotomous variable, with women having an academic education as a reference category.

(5) Age - a continuous variable measuring the actual age of the respondents.

(6) Health status - a dichotomous variable, with women having no chronic health condition as an omitted category.

\subsection{Statistical analyses}

First, a correlation analysis was conducted to examine the hypotheses at the bivariate level. The Spearman correlation test was chosen, since the dependent variable is ordinal. Then, regression analysis was employed to examine the effects of the predictors on the outcome variable. Since the outcome variable consists of five categories, it can be treated either as an ordinal or as a scale variable for the regression analysis. To determine which analysis fits best, ordinary least squares regression was conducted using all of the study variables in order to analyze the shape of the error distribution. The results (not shown here) indicate that the central tendency measures of the error distribution are not equal, meaning that this variable cannot be treated as an interval variable but rather as an ordinal variable. Therefore, we have adopted ordinal logistic regression analysis, which does not assume linear association between the predictors and the outcome variable. ${ }^{[49]}$ Several models were constructed in order to examine the effect of combinations of factors on the criterion variable. ${ }^{[50]}$ In all of them, the results of the Brant test of parallel lines were not significant, indicating that the ordinal regression was the most suitable multivariate analysis for this case.

\section{Results}

\subsection{Bivariate analysis}

The results of the bivariate analyses are shown in Table 3.

Table 3. Spearman correlations between the study variables

\begin{tabular}{|c|c|c|c|c|c|c|c|}
\hline & 1 & 2 & 3 & 4 & 5 & 6 & 7 \\
\hline 1. Marital status & --- & -0.01 & 0.16 & -0.05 & -0.17 & -0.13 & 0.19 \\
\hline 2. Education & & --- & -0.02 & -0.13 & 0.01 & 0.08 & 0.05 \\
\hline 3. Age & & & --- & 0.19 & 0.05 & 0.05 & -0.02 \\
\hline 4. Health condition & & & & --- & 0.04 & 0.13 & 0.03 \\
\hline 5. Search for OHI on social media & & & & & --- & -0.04 & $0.26^{*}$ \\
\hline 6. Cues to action & & & & & & --- & $0.33^{* *}$ \\
\hline 7. Intention to use social media for health purposes & & & & & & & --- \\
\hline
\end{tabular}

The results suggest that individuals who previously searched for $\mathrm{OHI}$ on social media are more likely to intend to use social media for health purposes in the future as compared to those who did not search $(r=0.26, p<.05)$. In addition, higher perception of the presence of cues to action increases the intention to use social media for health in the future $(r=0.33, p<.01)$. Therefore, Hypotheses 1 and 2 were confirmed on the bivariate level.

\subsection{Multivariate analysis}

Although these results are valuable, they are limited since bivariate analysis does not consider other variables that may challenge the findings. ${ }^{[51]}$ Therefore, multivariate analysis including several models was conducted in order to examine the factors predicting the outcome variable. In sum, five models were tested using different combinations of variables. Only the model with socio-demographic variables was not significant [Chi-square $(4)=2.85, p>.05$ ] and therefore is not shown in Table 4 . The rest of the models are significant 14 (at either .01 or .05 level) and demonstrate a good fit to the data.

As Table 4 shows, searching for $\mathrm{OHI}$ on social media has a positive and a significant effect on the criterion of intention to use social media for health purposes when controlling for other variables in the models, thereby confirming Hypothesis 1. In addition, cues to action demonstrate a positive and a significant effect at a 0.01 level in all the models that included this variable, while controlling for other variables in the models. This means that the higher the evaluation attributed to the cues to action, the higher the intention to use social media for health in the future. Concerning the sociodemographic variables, only marital status exhibited a significant effect on the outcome variable. In two of the three models, non-married women were found to have higher intention to use social media for health in the future than married/cohabitating women. Age, education and presence of chronic health condition had no impact. Therefore, Hypothesis 3 was partially supported. 
Table 4. Coefficients (standard errors) of ordinal regression analysis predicting intention to use social media for health purposes

\begin{tabular}{|c|c|c|c|c|}
\hline Variables & $\begin{array}{l}\text { Social media use and } \\
\text { cues to action }\end{array}$ & $\begin{array}{l}\text { Socio-demographic } \\
\text { and social media use }\end{array}$ & $\begin{array}{l}\text { Socio-demographic } \\
\text { and cues to action }\end{array}$ & All predictors \\
\hline Not at all & $\begin{array}{l}1.39^{* *} \\
(0.46)\end{array}$ & $\begin{array}{l}0.37 \\
(0.86)\end{array}$ & $\begin{array}{l}1.84 \\
(1.01)\end{array}$ & $\begin{array}{l}1.96 \\
(1.03)\end{array}$ \\
\hline Low extent & $\begin{array}{l}1.99^{* *} \\
(0.48)\end{array}$ & $\begin{array}{l}0.92 \\
(0.87)\end{array}$ & $\begin{array}{l}2.45^{*} \\
(1.02)\end{array}$ & $\begin{array}{l}2.64^{*} \\
(1.05)\end{array}$ \\
\hline Medium extent & $\begin{array}{l}3.28^{* *} \\
(0.56)\end{array}$ & $\begin{array}{l}2.15^{*} \\
(0.90)\end{array}$ & $\begin{array}{l}3.70^{* *} \\
(1.08)\end{array}$ & $\begin{array}{l}4.02^{* *} \\
(1.11)\end{array}$ \\
\hline High extent & $\begin{array}{l}3.78^{* *} \\
(0.59)\end{array}$ & $\begin{array}{l}2.59^{* *} \\
(0.92)\end{array}$ & $\begin{array}{l}4.14^{* *} \\
(1.10)\end{array}$ & $\begin{array}{l}4.50^{* * *} \\
(1.14)\end{array}$ \\
\hline Search for OHI on social media $($ yes $=1$ ) & $\begin{array}{l}1.33^{* *} \\
(0.45)\end{array}$ & $\begin{array}{l}1.48^{* *} \\
(0.51)\end{array}$ & - & $\begin{array}{l}1.69^{* *} \\
(0.53)\end{array}$ \\
\hline Cues to action & $\begin{array}{l}0.29^{* *} \\
(0.08)\end{array}$ & - & $\begin{array}{l}0.30^{* *} \\
(0.09)\end{array}$ & $\begin{array}{l}0.34^{* *} \\
(0.10)\end{array}$ \\
\hline Marital status (non-married $=1$ ) & - & $\begin{array}{l}1.34^{*} \\
(0.65)\end{array}$ & $\begin{array}{l}1.14 \\
(0.65)\end{array}$ & $\begin{array}{l}1.63^{*} \\
(0.69)\end{array}$ \\
\hline Education $($ non-academic $=1)$ & - & $\begin{array}{l}0.18 \\
(0.45)\end{array}$ & $\begin{array}{l}-0.001 \\
(0.46)\end{array}$ & $\begin{array}{l}0.03 \\
(0.47)\end{array}$ \\
\hline Age & - & $\begin{array}{l}-0.002 \\
(0.02)\end{array}$ & $\begin{array}{l}0.01 \\
(0.02)\end{array}$ & $\begin{array}{l}0.00 \\
(0.02)\end{array}$ \\
\hline Chronic health condition $($ yes $=1$ ) & - & $\begin{array}{l}-0.06 \\
(0.48)\end{array}$ & $\begin{array}{l}-0.32 \\
(0.50)\end{array}$ & $\begin{array}{l}-0.34 \\
(0.51)\end{array}$ \\
\hline -2log likelihood & 112.99 & 185.84 & 184.31 & 175.62 \\
\hline Nagelkerke's R Square & 0.20 & 0.15 & 0.19 & 0.30 \\
\hline
\end{tabular}

\section{DiscuSSION}

The goal of this study was to examine the factors affecting intention to use social media for health purposes among Jewish women in Israel. For this goal, several variables reflecting three theoretical perspectives were used. The results mostly support each of these perspectives.

First, in line with the results of previous studies, ${ }^{[4,22]}$ an association was found between searching for $\mathrm{OHI}$ on social media and the outcome variable, thus completely supporting Hypothesis 1 on both the bivariate and the multivariate levels. It seems that women who previously searched for $\mathrm{OHI}$ were empowered by their searching and by their desire to continue being empowered. Thus, women should keep on searching for $\mathrm{OHI}$ on social media while healthcare providers should encourage them to do so.

Second, cues to action were found to be positively associated with the dependent variable, similar to the findings of other studies, ${ }^{[38,52]}$ thus completely supporting Hypothesis 2 on both levels. The existence of triggers motivates behavioral change, especially when these triggers are highly relevant for the individuals. Indeed, the "pressure" created by these triggers seems to "push" women to intend to use social media for health.

Third, no effects of socioeconomic variables were found ex- cept for that of marital status, thus very partially supporting Hypothesis 3. The intention of non-married women may stem from the fact that in most cases they do not receive health-related social control on an everyday basis ${ }^{[41]}$ as opposed to married women, who both provide and receive such control. Thus, the limited scope of social control leads nonmarried women to rely on social media in health-related issues and to intend to use social media in the future.

\section{Conclusions}

This study is one of the few quantitative studies investigating the use of social media for health. It has contributed to understanding factors affecting the intention to use social media for health purposes among a specific population, i.e., women, from the health perspective. The results indicate that health empowerment and health beliefs approaches explain the intention to use social media for health purposes better and more consistently than the digital inequality approach. This is somewhat encouraging in that socioeconomic background plays a much smaller role than other factors. Thus, the work of the community should be directed at increasing women's health-related experience with social media and improving their health beliefs. 


\section{Limitations}

This study has several limitations. First, the data are selfreported. Therefore, misclassifications in variables are probable. ${ }^{[21]}$ Second, although the models were significant and allowed prediction of the phenomenon, the sample was relatively small. Third, the study was conducted in Hebrew only, thereby including the Jewish population for the most part and thus restricting the ability to generalize the findings for the entire population of the country. Finally, the variables are used in a limited way. The cues to action variable was measured by summing up scores of two items, even though this variable is usually constructed using more items. ${ }^{[5]}$ This was done in order to measure health beliefs in a parsimonious yet effective way. Note that HBM variables were only a part of the questionnaire. Future studies should concentrate on HBM variables only and examine this model in a separate study, also using both of the health-related social media use variables.

\section{CONFliCtS OF INTEREST Disclosure}

The authors declare they have no conflicts of interest.

\section{REFERENCES}

[1] Murthy D, Gross A, Oliveira D. Understanding cancer-based networks in Twitter using Social Network Analysis. Proceedings of the 5th IEEE International Conference on Semantic Computing; 2011 Sep 18-21. Palo Alto, CA. London, UK: IEEE; 2011. 559-66 p. PMid: 21516088. https://doi.org/10.1109/ICSC. 2011.51

[2] McKinley C, Wright PJ. Informational social support and online health information seeking: examining the association between factors contributing to healthy eating behavior. Comput Human Behav. 2014; 37: 107-16. https://doi.org/10.1016/j.dss. 2012.10 047

[3] Xiao N, Sharman R, Rao HR, et al. Factors influencing online health information search: an empirical analysis of a national cancerrelated survey. Decis Support Syst. 2014; 57: 417-27. https: //doi.org/10.1016/j.dss.2012.10.047

[4] Mano RS. Social media and online health services: a health empowerment perspective to online health information. Comput Human Behav 2014; 39: 404-12. https://doi.org/10.1016/j.chb. 2014.07. 032

[5] Ahadzadeh AS, Sharif SP, Ong FS, et al. Integrating health belief model and technology acceptance model: an investigation of healthrelated Internet use. J Med Internet Res. 2015; 17(2): e45-e45. PMid: 25700481. https://doi.org/10.2196/jmir. 3564

[6] Antheunis ML, Tates K, Nieboer TE. Patients' and health professionals' use of social media in health care: motives, barriers and expectations. Patient Educ Couns. 2013; 92(3): 426-31. PMid: 23899831. https://doi.org/10.1016/j.pec. 2013.06.020

[7] Penni J. The online evolution of social media: an extensive exploration of a technological phenomenon and its extended use in various activities. Huddersfield, UK: University of Huddersfield; 2015. Available from: http://eprints.hud.ac.uk/28332

[8] Merolli M, Gray K, Martin-Sanchez F. Health outcomes and related effects of using social media in chronic disease management: a literature review and analysis of affordances. J Biomed Inform. 2013; 46(6): 957-69. PMid: 23702104. https ://doi.org/10.1016/j. jbi.2013.04.010

[9] Zhang Y, He D, Sang Y. Facebook as a platform for health information and communication: a case study of a diabetes group. J Med Syst. 2013; 37(3): 9942-53. PMid: 23588823. https: //doi.org/10.1007/s10916-013-9942-7

[10] Sarasohn-Kahn J. The wisdom of patients: Health care meets online social media. Oakland (CA): California Health Care Foundation; 2008. Available from: https://www .chcf.org/publication/the-wisdom-o

f-patients-health-care-meets-online-social-media/

[11] Househ M, Borycki E, Kushniruk A. Empowering patients through social media: the benefits and challenges. Health Inform J. 2014; 20(1): 50-8. PMid: 24550564 . https://doi.org/10.1177/1460 458213476969

[12] Benetoli A, Chen TF, Aslani P. How patients' use of social media impacts their interactions with healthcare professionals. Patient Educ Couns. 2018; 101(3): 439-44. PMid: 28882545. https: //doi.org/10.1016/j.pec.2017.08.015

[13] Scanfeld D, Scanfeld V, Larson EL. Dissemination of health information through social networks: Twitter and antibiotics. Am J Infect Control. 2010; 38(3): 182-8. PMid: 20347636. https : //doi.org/10.1016/j.ajic.2009.11.004

[14] Sharma P, Kaur PD. Effectiveness of web-based social sensing in health information dissemination - a review. Telematics Inform. 2017; 34(1): 194-219. https://doi.org/10.1016/j.tele.2016.04 .012

[15] Madathil KC, Greenstein JS, Koikkara R. An investigation of the factors that predict a healthcare consumer's use of anecdotal healthcare information available on the Internet. Proceedings of the $\mathrm{Hu}$ man Factors and Ergonomics Society Annual Meeting (Vol. 58). Sage CA: Los Angeles, CA: SAGE Publications; 2014. 604-8 p. https://doi.org/10.1177/1541931214581129

[16] Thackeray R, Crookston BT, West JH. Correlates of health-related social media use among adults. J Med Internet Res. 2013; 15(1): e21. PMid: 23367505. https://doi.org/10.2196/jmir. 2297

[17] Abdrbo A, Hassanein S. Effect of internet use for health information and internet addiction on adolescents female high school' health lifestyle. J Nurs Educ Pract. 2017; 7(12): 10-9. https: //doi.org/10.5430/jnep.v7n12p10

[18] Lev E. Prenatal googling: online information seeking by Israeli women during pregnancy. Int Rev Soc Res. 2013; 3(2): 69-87. https://doi.org/10.1515/irsr-2013-0011

[19] Zhang Y. Understanding the sustained use of online health communities from a self-determination perspective. J Assoc Inf Sci Technol. 2016; 67(12): 2842-57. https://doi.org/10.1002/asi. 23560

[20] Chen W, Lee K-H. More than search? Informational and participatory ehealth behaviors. Comput Human Behav. 2014; 30: 103-9. https://doi.org/10.1016/j.chb.2013.07.028

[21] Koo M, Lu MC, Lin SC. Predictors of Internet use for health information among male and female Internet users: findings from the 2009 Taiwan National Health Interview Survey. Int J Med Inform. 2016; 
94:155-63. PMid: 27573323. https://doi.org/10.1016/j.ij medinf.2016.07.011

[22] Mano R. Online health information and health changes: a gender approach to technology and health empowerment among Jewish women in Israel. J Community Med Public Health Care. 2016; 3 : 023. https://doi .org/10.24966/CMPH-1978/100023

[23] Lee YJ, Boden-Albala B, Larson E, et al. Online health information seeking behaviors of Hispanics in New York City: a communitybased cross-sectional study. J Med Internet Res. 2014; 16(7). PMid: 25092120. https://doi.org/10.2196/jmir. 3499

[24] Venkatesh V, Davis FD. A theoretical extension of the Technology Acceptance Model: four longitudinal field studies. Manag Sci. 2000; 46(2): 186-204. https://doi.org/10.1287/mnsc.46.2. 186.11926

[25] Lean OK, Zailani S, Ramayah T, et al. Factors influencing intention to use e-government services among citizens in Malaysia. Int J Inf Manag. 2009; 29(6): 458-75. https://doi.org/10.1016/j.ij infomgt . 2009.03.012

[26] Rehman M, Esichaikul V, Kamal M. Factors influencing egovernment adoption in Pakistan. Transform Gov: People, Process, Policy. 2012; 6(3): 258-82. https ://doi .org/10.1108/175061 61211251263

[27] Mesch GS. Ethnic origin and access to electronic health services. Health Inform J. 2016; 22(4): 1-13. PMid: 26261219. https: //doi.org/10.1177/1460458215590863

[28] Magnezi R, Grosberg D, Novikov I, et al. Characteristics of patients seeking health information online via social health networks versus general Internet sites: a comparative study. Inform Health Soc Care. 2015; 40(2): 125-38. PMid: 24475937. https://doi.org/10.3 $109 / 17538157.2013 .879147$

[29] Rosenberg D, Mano R, Mesch G. They have needs, they have goals: using communication theories to explain health-related social media use and health behavior change. MOJ Public Health. 2017; 6(2): 288-94. https://doi.org/10.15406/mojph.2017.06.00163

[30] Lemire M, Sicotte C, Pare G. Internet use and the logics of personal empowerment in health. Health Policy. 2008; 88(1): 13040. PMid: 18436330 . https://doi.org/10.1016/j.healthpo 1.2008 .03 .006

[31] Lewis N, Martinez LS, Freres DR, et al. Seeking cancer-related information from media and family/friends increases fruit and vegetable consumption among cancer patients. Health Commun. 2012; 27(4): 380-8. PMid: 21932985. https ://doi .org/10.1080/10410236 .2011 .586990

[32] Drenthea P, Goldner M, Cotten S, et al. The association among gender, computer use and online health searching, and mental health. Inf Commun Soc. 2008; 11(4): 509-25. https://doi.org/10.1080/ 13691180801999019

[33] Oh HJ, Lauckner C, Boehmer J, et al. Facebooking for health: an examination into the solicitation and effects of health-related social support on social networking sites. Comput Human Behav. 2013; 29(5): 2072-80. https://doi.org/10.1016/j.chb.2013.04.017

[34] Redding CA, Rossi JS, Rossi SR, et al. Health behavior models. Int Electron J Health Educ. 2000; 3: 180-93. Available from: http://citeseerx.ist.psu.edu/viewdoc/summary? doi=10.1.1.114.6724

[35] Sutton S. Health behavior: psychosocial theories. Int Ency Soc Behav Sci. 2001; 6499-6506. https://doi.org/10.1016/B0-08-043 076-7/03872-9

[36] Carpenter CJ. A meta-analysis of the effectiveness of Health Belief Model variables in predicting behavior. Health Commun. 2010; 25(8): 661-9. PMid: 21153982. https ://doi .org/10.1080/10410236 .2010 .521906

Published by Sciedu Press
[37] Champion VL, Skinner CS. The Health Belief Model. In: Glanz, K, Rimer, BK, Viswanath, K. (eds.) Health Behavior and Health Education: Theory, Research and Practice (4th ed.). Hoboken, NJ: John Wiley \& Sons; 2008. 83-104 p.

[38] Akompab DA, Bi P, Williams S, et al. Heat waves and climate change: applying the health belief model to identify predictors of risk perception and adaptive behaviors in Adelaide, Australia. Int J Environ Res Public Health. 2013; 10(6): 2164-84. PMid: 23759952 https://doi.org/10.3390/ijerph10062164

[39] Igarashi T, Takai J, Yoshida T. Gender differences in social network development via mobile phone text messaging: a longitudinal study. J Soc Pers Relat. 2005; 22(5): 691-713. https ://doi .org/10.1 $177 / 0265407505056492$

[40] Venkatesh V, Morris MG. Why don't men ever stop to ask for directions? Gender, social influence, and their role in technology acceptance and usage behavior. MIS Q. 2000; 24(1): 115-39. https://doi.org/10.2307/3250981

[41] August KJ, Sorkin DH. Marital status and gender differences in managing a chronic illness: the function of health-related social control. Soc Sci Med. 2010; 71: 1831-8. PMid: 20889249. https : //doi.org/10.1016/j.socscimed.2010.08.022

[42] Chew F, Palmer S, Kim S. Testing the influence of the health belief model and a television program on nutrition behavior. Health Commun. 1998; 10(3): 227-45. PMid: 16370984. https://doi.org/ $10.1207 /$ s15327027hc1003_3

[43] Lissitsa S, Chachashvili-Bolotin S. Use of the Internet in capital enhancing ways - ethnic differences in Israel and the role of language proficiency. Int J Internet Sci. 2014; 9(1): 9-30.

[44] Mesch GS. Minority status and the use of computer-mediated communication: a test of the social diversification hypothesis. Commun Res. 2012; 39(3): 317-37. https://doi.org/10.1177/009365 0211398865

[45] Raijman R. South African Jews in Israel: Assimilation in multigenerational perspective. Lincoln, NE: University of Nebraska Press; 2016. https://doi.org/10.2307/j.ctt1d989bn

[46] Zucco R, Lavano F, Anfosso R, et al. Internet and social media use for antibiotic-related information seeking: findings from a survey among adult population in Italy. Int J Med Inform. 2018; 111 : 131-9. PMid: 29425624. https ://doi.org/10.1016/j.ijmedi nf.2017.12.005

[47] Setbon M, Raude J. Factors in vaccination intention against the pandemic influenza A/H1N1. Eur J Public Health. 2010; 20(5): 490-4. PMid: 20444821. https://doi.org/10.1093/eurpub/ckq054

[48] Sharma KS. Adoption of e-government services: the role of service quality dimensions and demographic variables. Transform Gov: People, Process, Policy. 2015; 9(2): 207-22. https ://doi .org/10.1 108/TG-10-2014-0046

[49] Lee A, Levy Y. The effect of information quality on trust in egovernment systems' transformation. Transform Gov: People, Process, Policy. 2014; 8(1): 76-100. https://doi .org/10.1108/TG $-10-2012-0011$

[50] Raijman R, Semyonov M, Geffen R. Language proficiency among post-1990 immigrants in Israel. J Ethn Migr Stud. 2015; 41(8): 134771. https://doi.org/10.1080/1369183X.2014.982523

[51] Mesch G, Talmud I. The quality of online and offline relationships: the role of multiplexity and duration of social relationships. Inf Soc. 2006; 22(3): 137-48. https://doi.org/10.1080/0197224060 0677805

[52] Hsieh HL, Tsai CH. An empirical study to explore the adoption of telehealth: Health Belief Model perspective. J Eng Sci Technol Rev. 2013; 6(2): 1-5. https://doi.org/10.25103/jestr.062.01 